Author affiliations appear at the end of this article.

Published online ahead of print at www.jco.org on December 7, 2015.

The study was supported by a grant from the French Ministry of Health (Projet Hospitalier de Recherche Clinique of France [PHRC 2003 No. 13-2]). The Macintyre laboratory was supported by the Fondation de France, the Association de Recherche sur le Cancer, Cent pour Sang la Vie, and the Société Française des Cancers de l'Enfant. CHUGAI PHARMA France provided technical and financial support.

Presented at the 56th Annual Meeting of the American Society of Hematology, San Francisco, CA, December 6-9, 2014.

Authors' disclosures of potential conflicts of interest are found in the article online at www.jco.org. Author contributions are found at the end of this article.

Corresponding author: Stéphane Lepretre, MD, Département d'Hématologie, Centre Henri-Becquerel, rue d'Amiens, Rouen Cedex 76038, France; e-mail: stephane.lepretre@chb. unicancer.fr.

C 2015 by American Society of Clinical Oncology

0732-183X/16/3406w-572w/\$20.00 DOI: $10.1200 / J C O .2015 .61 .5385$

\title{
Pediatric-Like Acute Lymphoblastic Leukemia Therapy in Adults With Lymphoblastic Lymphoma: The GRAALL-LYSA LL03 Study
}

\begin{abstract}
Stéphane Lepretre, Aurore Touzart, Thomas Vermeulin, Jean-Michel Picquenot, Aline Tanguy-Schmidt, Gilles Salles, Thierry Lamy, Marie-Christine Béné, Emmanuel Raffoux, Françoise Huguet, Patrice Chevallier, Serge Bologna, Réda Bouabdallah, Jacques Benichou, Josette Brière, Anne Moreau, Valérie Tallon-Simon,
\end{abstract} Stéphanie Seris, Carlos Graux, Vahid Asnafi, Norbert Ifrah, Elizabeth Macintyre, and Hervé Dombret

See accompanying article on page 533

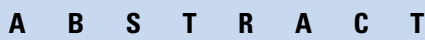

\section{Purpose}

This study evaluated the efficacy of pediatric-like acute lymphoblastic leukemia (ALL) therapy in adults with lymphoblastic lymphoma (LL).

\section{Patients and Methods}

This was a prospective phase II study in adults 18 to 59 years old with previously untreated LL. Patients were treated with an adapted pediatric-like ALL protocol, which included a corticosteroid prephase, a fivedrug induction reinforced by sequential cyclophosphamide administration, dose-dense consolidation, late intensification, CNS prophylaxis, and a 2-year maintenance phase. Treatment response was assessed by computed tomography and optional positron emission tomography. Allogeneic hematopoietic stem cell transplant was offered to selected patients in first complete remission (CR) or unconfirmed CR.

\section{Results}

The study enrolled 148 patients (131 with T-lineage LL [T-LL] and 17 with B-lineage LL [B-LL]). A total of 119 patients with T-LL $(90.8 \%)$ and 13 with B-LL (76.5\%) reached CR/unconfirmed CR, including 26 with T-LL and two with B-LL who needed a second induction salvage course. Relapse occurred in 34 patients with T-LL and four with B-LL. In patients with T-LL, 3-year event-free survival was $63.3 \%$ ( $95 \% \mathrm{Cl}, 54.2 \%$ to $71.0 \%$ ), disease-free survival was $72.4 \%$ (95\% Cl, 63.0\% to $79.7 \%)$, and overall survival was $69.2 \%(95 \% \mathrm{Cl}, 60.0 \%$ to $76.7 \%)$. Multivariate analysis identified serum lactate dehydrogenase level and the NOTCH1/FBXW7/RAS/PTEN oncogene (a four-gene oncogenetic classifier) status but not positron emission tomography or hematopoietic stem cell transplant as independent prognostic factors for outcome in T-LL.

\section{Conclusion}

In adults with $L L$, an intensive pediatric-like $A L L$ treatment protocol was associated with a good response rate and outcome. In patients with $T-L L$, the four-gene oncogenetic classifier and lactate dehydrogenase level were independent prognostic indicators.

\section{J Clin Oncol 34:572-580. (C) 2015 by American Society of Clinical Oncology}

\section{INTRODUCTION}

Lymphoblastic lymphoma (LL) is a rare and aggressive form of non-Hodgkin lymphoma (NHL) that most often affects young men. ${ }^{1}$ In the current WHO classification, LL is grouped with acute lymphoblastic leukemia (ALL), although it is arbitrarily differentiated from ALL by the presence of less than 20\% marrow blasts. Most cases of LL $(>80 \%)$ are T-lineage (T-LL); the rest are B-lineage (B-LL). At presentation, most patients with LL have advanced disease with multiorgan involvement, including mediastinal masses. Patients with LL may also have bone marrow involvement ( $<20 \%$ of cases) and CNS involvement (5\% to $10 \%$ of cases). ${ }^{2}$ Management of patients with LL is often difficult because of the aggressiveness of the disease and frequent mediastinal enlargement, which require urgent diagnosis and treatment.

Until recently, adult patients with LL were treated according to conventional NHL or ALL protocols. ${ }^{1,3}$ Response rates of $55 \%$ to $79 \%$ have been reported with NHL protocols, but overall 
survival (OS) has been unsatisfactory because of frequent relapse, often related to spread of the disease to the CNS. ${ }^{4}$ In a retrospective analysis of 92 patients with LL who were included in the French LNH-87/93 trials, 5-year event-free survival (EFS) was only $22 \%$ and 5-year OS only 32\%. ${ }^{5}$ Better results have been obtained using ALL protocols, with response rates of $55 \%$ to $100 \%$ and improved long-term survival. ${ }^{4}$

Although ALL-like intensive therapy is now considered the best option for treating adult LL, it is not yet standardized. The roles of mediastinal irradiation in patients with a high tumor burden, cranial irradiation as part of CNS prophylaxis, and autologous or allogeneic hematopoietic stem cell transplantation (HSCT) as consolidation therapy for high-risk patients continue to be debated. ${ }^{1,3,4}$ Several reports have shown that younger adults with ALL benefit from pediatric-like treatment protocols, ${ }^{6}$ but whether these protocols might also benefit adult patients with LL has been unclear.

We report here the results of the LL03 phase II study, which was conducted by the Group for Research on Adult ALL (GRAALL) and the Lymphoma Study Association (LYSA). Adult patients with LL were prospectively treated with a pediatric-like regimen adapted from the GRAALL protocol, previously shown to provide good responses in adult ALL. ${ }^{7}$ The study examined outcome of the treatment and investigated potential prognostic factors, including oncogenetic markers, as well as the influence of $\left[{ }^{18} \mathrm{~F}\right]$ fluorodeoxyglucose positron emission tomography (PET) and allogeneic HSCT.

\section{PATIENTS AND METHODS}

\section{Study Design}

This single-arm, phase II study was conducted between 2004 and 2012 at 58 centers in France and Belgium (ClinicalTrials.gov registry no. NCT00195871). The primary objective was to evaluate the efficacy of pediatric-like ALL therapy in adults age 18 to 59 years with newly diagnosed, previously untreated LL, as assessed by EFS. Secondary objectives were to determine response rate, disease-free survival (DFS), OS, and progression/relapse rate; and to identify prognostic factors, including early response to therapy (assessed by computerized tomography $[\mathrm{CT}]$ and PET scans) and oncogenetic markers, in patients with T-LL. The study was performed in accordance to the Declaration of Helsinki and local laws. The protocol was approved by the Comite de Protection des Personnes Nord-ouest I in France and the independent ethics committees of each institution in Belgium. All patients provided written informed consent.

\section{Patients}

Adults 18 to 59 years of age with diffuse, previously untreated LL at any stage, diagnosed according to WHO 2008 criteria, ${ }^{8}$ were considered for enrollment. Patients had to be able to submit to regular monitoring and could not have a contraindication to anthracyclines, general or visceral contraindications to intensive treatment, infection with HIV, previous treatment with chemotherapy, lymphoblastic blast crisis of chronic myeloid leukemia, or malignant tumors except for basal cell carcinoma or carcinoma in situ of the cervix. Women of childbearing age had to have a negative pregnancy test.

\section{Baseline Assessments}

At enrollment, a biopsy of the tumor mass and a sternal or iliac bone marrow aspirate and/or trephine were performed in all patients, whenever possible. When present, a sample of pleural or peritoneal fluid was collected.
The disease was staged according to the Ann Arbor system. ${ }^{9}$ Whenever possible, immunophenotypic, cytogenetic, and molecular status was determined from diagnostic cells or tissue. In T-LL cases, gene screening included NOTCH1/FBXW7 (N/F) mutations, N/K-RAS mutations, PTEN alterations, and T-cell receptor (TCR) gene rearrangements. ${ }^{10-12}$ Only samples with $\geq 50 \%$ infiltration by pathologic cells were considered interpretable for oncogenetic status. As described previously, ${ }^{11}$ patients with T-LL were defined as having a favorable four-gene oncogenetic classifier if they had an $N / F$ mutation in the absence of RAS or PTEN abnormalities; all other patients were defined as having an unfavorable four-gene classifier. Immunophenotype was classified according to the European Group for the Immunologic Classification of Leukaemias. ${ }^{13}$ Performance status was assessed using the Eastern Cooperative Oncology Group criteria (ECOG-PS). ${ }^{14}$ All patients had a thoraco-abdominal-pelvic CT scan with IV injection of iodine and optional gallium scan or 18-deoxyglucose PET scan; a complete and differential blood count; standard blood biochemistry analyses, including lactate dehydrogenase (LDH) and $\beta-2$ microglobulin levels; standard immunohematology, hemostasis, and virology serology; and human leukocyte antigen (HLA) typing.

\section{Treatment}

All patients received an adapted GRAALL protocol consisting of a corticosteroid prephase, a five-drug induction with sequential administration of cyclophosphamide (hyperC sequence), dose-dense consolidation, late intensification, CNS prophylaxis with intrathecal chemotherapy and cranial irradiation, and a 2-year maintenance phase (Data Supplement). ${ }^{7}$ Allogeneic HSCT was offered in first complete remission (CR) or unconfirmed complete remission $(\mathrm{CRu})$ to patients with high-risk disease who had an HLA siblingmatched donor or who had a fully matched unrelated donor (ie, 10 of 10 HLA matched). Patients were considered to have high-risk disease if they had clinical or cytologic CSF CNS involvement or required a second induction salvage course to reach $\mathrm{CR}$ or $\mathrm{CRu}$.

\section{Assessment During and After Treatment}

Early sensitivity to chemotherapy was assessed locally on day 8 of induction therapy. Treatment response was determined by CT scan and using Cheson criteria. ${ }^{15}$ After completion of the study, histologic findings were centrally reviewed by LYSA pathologists for approximately $70 \%$ of the patients. Survival measures are defined in the Data Supplement.

\section{Study Size Calculation}

The targeted study size was 120 patients. This was estimated to provide $20 \%$ precision (maximal $95 \%$ CI width) in the EFS and given a $20 \%$ dropout rate.

\section{Statistical Analysis}

Statistical analysis was performed using SAS version 9.3 (SAS Institute, Cary, NC). Analyses were performed in the full analysis set, defined as all patients with LL who received treatment. $P$ values less than 0.05 were considered to be statistically significant. EFS, DFS, and OS were estimated by the Kaplan-Meier method. DFS was estimated from patients who experienced $\mathrm{CR}$ or $\mathrm{CRu}$ following induction or salvage therapy. A Cox model was used for estimation of hazard ratios (HRs). Candidate prognostic factors for survival measures (Data Supplement) were first assessed by univariate analysis using a log-rank test. Multivariate analysis was performed with the following cofactors: age, Ann Arbor stage, LDH, ECOG-PS, and all factors with $P<.10$ in the univariate analysis. Factors were excluded from the multivariate analyses if greater than $10 \%$ of the values were missing. The proportional hazard assumption was confirmed graphically and by an interaction test between time and each independent variable in the Cox models. 


\section{RESULTS}

\section{Patients}

Between 2004 and 2012, 155 patients were recruited. Data were missing for one patient. On histologic review, two patients were reclassified as having diffuse large B-cell NHL, one with NHL of unknown type, and three with thymoma. Of the remaining 148 patients, 131 had T-LL and 17 had B-LL (Table 1). All patients had less than 20\% marrow blasts. Most patients with T-LL were male $(80.2 \%)$, whereas B-LL patients included nearly equal numbers of men $(52.9 \%)$ and women $(47.1 \%)$. Ages were similar for both subtypes (median, 37 years for B-LL and 33 years for T-LL). Most patients were asymptomatic or completely ambulatory (ECOG-PS 0 or 1), even though most had advanced disseminated disease (Ann Arbor stage 4). Most patients with T-LL had mediastinal involvement (94.7\%) and about one-half had serous involvement (53.4\%), but few had nonserous extranodal involvement (22.9\%), whereas most patients with B-LL had nonserous extranodal involvement $(58.8 \%)$ but not mediastinal $(23.5 \%)$ or serous $(17.6 \%)$ involvement. Approximately one-quarter of the patients in both groups had medullary involvement (25.0\% B-LL, 26.6\% T-LL). Few

\begin{tabular}{|c|c|c|}
\hline Characteristic & $\begin{array}{c}\mathrm{B}-\mathrm{LL} \\
(\mathrm{N}=17)\end{array}$ & $\begin{array}{c}\mathrm{T}-\mathrm{LL} \\
(\mathrm{N}=131)\end{array}$ \\
\hline \multicolumn{3}{|l|}{ Sex, no. (\%) } \\
\hline Male & 9 (52.9) & $105(80.2)$ \\
\hline Female & $8(47.1)$ & $26(19.8)$ \\
\hline \multicolumn{3}{|l|}{ Age, years } \\
\hline Mean $\pm S D$ & $38.3 \pm 14.9$ & $35.0 \pm 12.1$ \\
\hline Median & 37 & 33 \\
\hline Range & $19-58$ & $18-59$ \\
\hline \multicolumn{3}{|l|}{ ECOG-PS, no. (\%) } \\
\hline 0 & $7(41.2)$ & $56(42.7)$ \\
\hline 1 & $6(35.3)$ & $57(43.5)$ \\
\hline 2 & $2(11.8)$ & $16(12.2)$ \\
\hline 3 & $2(11.8)$ & $1(0.8)$ \\
\hline 4 & $0(0.0)$ & $1(0.8)$ \\
\hline CNS involvement, $\mathrm{n} / \mathrm{N}(\%)$ & 2/17 (11.8) & 6/131 (4.6) \\
\hline Mediastinal involvement, n/N (\%) & $4 / 17(23.5)$ & $124 / 131(94.7)$ \\
\hline Nonserous extranodal involvement, n/N (\%) & 10/17 (58.8) & $30 / 131(22.9)$ \\
\hline Serous involvement, $\mathrm{n} / \mathrm{N}(\%)$ & 3/17 (17.6) & $70 / 131(53.4)$ \\
\hline \multicolumn{3}{|l|}{ Ann Arbor stage, no. $(\%)^{*}$} \\
\hline 1 & $1(5.9)$ & $14(10.8)$ \\
\hline 2 & $3(17.6)$ & 22 (16.9) \\
\hline 3 & $0(0.0)$ & $15(11.5)$ \\
\hline 4 & $13(76.5)$ & 79 (60.8) \\
\hline Medullary involvement, n/N (\%) & $4 / 16(25.0)$ & $34 / 128(26.6)$ \\
\hline \multicolumn{3}{|l|}{ Peripheral blood blasts, \%† } \\
\hline Median & 0.0 & 0.0 \\
\hline Interquartile range & 0.0 & 0.0 \\
\hline Range & $0.0-0.1$ & $0.0-1.5$ \\
\hline \multicolumn{3}{|l|}{ LDH concentration, no. $(\%)^{*}$} \\
\hline Normal range & $9(52.9)$ & $38(29.2)$ \\
\hline $1.1-1.9 \times$ normal limit & $4(23.5)$ & $47(36.2)$ \\
\hline 2.0-3.9 $\times$ normal limit & $2(11.8)$ & $38(29.2)$ \\
\hline 4.0-9.9 $\times$ normal limit & $2(11.8)$ & $7(5.4)$ \\
\hline \multicolumn{3}{|c|}{$\begin{array}{l}\text { Abbreviations: B-LL, B-type lymphoblastic leukemia; ECOG-PS, Eastern } \\
\text { Cooperative Oncology Group performance status; LDH, lactate dehydrogenase; } \\
\text { T-LL, T-type lymphoblastic leukemia. } \\
{ }^{*} N=130 \text { patients with T-LL. } \\
\text { †N }=127 \text { patients with T-LL. }\end{array}$} \\
\hline
\end{tabular}

patients had CNS involvement (11.8\% B-LL, 4.6\% T-LL), and few or no blasts were detected by cytology in the peripheral blood of patients in either group (median, $0.0 \%$ [range, $0.0 \%$ to $0.1 \%$ ] for B-LL and $0.0 \%$ [range, $0.0 \%$ to $1.5 \%$ ] for T-LL).

\section{Response to Therapy}

All 17 patients with B-LL and 125 of the patients with T-LL completed the study according to protocol. One patient with T-LL received HSCT not according to protocol, one received radiotherapy not according to protocol, and three partial responders received consolidation treatment without salvage treatment.

$T-L L$. Of the 131 patients with T-LL, 119 (90.8\%) attained CR or CRu after induction or salvage treatment (Fig 1). Thirty patients (25.2\%) needed a salvage course, and 34 (26.0\%) relapsed (median follow-up, 35.7 months). Of the 34 patients who relapsed, seven had received salvage therapy to reach $\mathrm{CR}$ or $\mathrm{CRu}$, and 14 had mediastinal relapse. At 3 years, EFS was estimated at 63.3\% (95\% CI, $54.2 \%$ to $71.0 \%$; median follow-up, 30.3 months), DFS at $72.4 \%$ (95\% CI, $63.0 \%$ to $79.7 \%$; median follow-up, 57.7 months), and OS at $69.2 \%(95 \% \mathrm{CI}, 60.0 \%$ to $76.7 \%$; median follow-up, 35.7 months) (Fig 2). Overall, 88 patients with T-LL attained first complete remission, one attained second complete remission, two relapsed, and 40 died.

$B-L L$. Of the 17 patients with B-LL, $13(76.5 \%)$ attained CR or CRu after induction or salvage treatment (Fig 1). Four patients needed a salvage course and four relapsed. Of the four patients who relapsed, none had received salvage therapy to reach CR or CRu. At 3 years, EFS, DFS, and OS were not estimated for B-LL because of the low number of patients. Overall, 10 patients with B-LL attained first complete remission, one attained stable disease, and six died.

Deaths, grade 3/4 adverse events, and serious adverse events. A total of 40 patients died during the study: five died because of induction toxicity, three because of allograft toxicity, one for an unknown reason, and 31 because of relapse or progression (Data Supplement). Grade 3/4 adverse events and the numbers of patient experiencing serious adverse events are summarized in the Data Supplement.

\section{Prognostic Factors in $T$ - $L L$}

Because few patients had B-LL, prognostic analysis was only performed in patients with T-LL.

Oncogenetic factors. Fifty-four patients had diagnostic material with at least $50 \%$ infiltration (fresh or cryopreserved pleural or pericardial samples $[n=7]$ or tissue biopsies [ $=47]$ ). The clinical characteristics, EFS, DFS, and OS for these patients did not differ significantly from the overall group (data not shown). N/F mutations were found in 51.9\% (27 of 52) of the patients. RAS/PTEN alterations were found in $27.1 \%$ (13 of 48 patients). In univariate analysis, the presence of a high-risk genetic profile, as assessed by our four-gene oncogenetic classifier, ${ }^{11}$ was associated with shorter EFS, DFS, and OS (Fig 2; Data Supplement). After adjustment for age, LDH level, Ann Arbor stage, and ECOG-PS, the four-gene oncogenetic classifier was confirmed to be an independent prognostic indicator for EFS (HR, 20.5 [95\% CI, 2.6 to 164.1]; $P=0.0045)$, DFS (HR, 12.6 [95\% CI, 1.5 to 104.8]; $P=.019$ ), and OS (HR, 17.0 [95\% CI, 2.1 to 136.8 ]; $P=.0078$ ) (Table 2). 


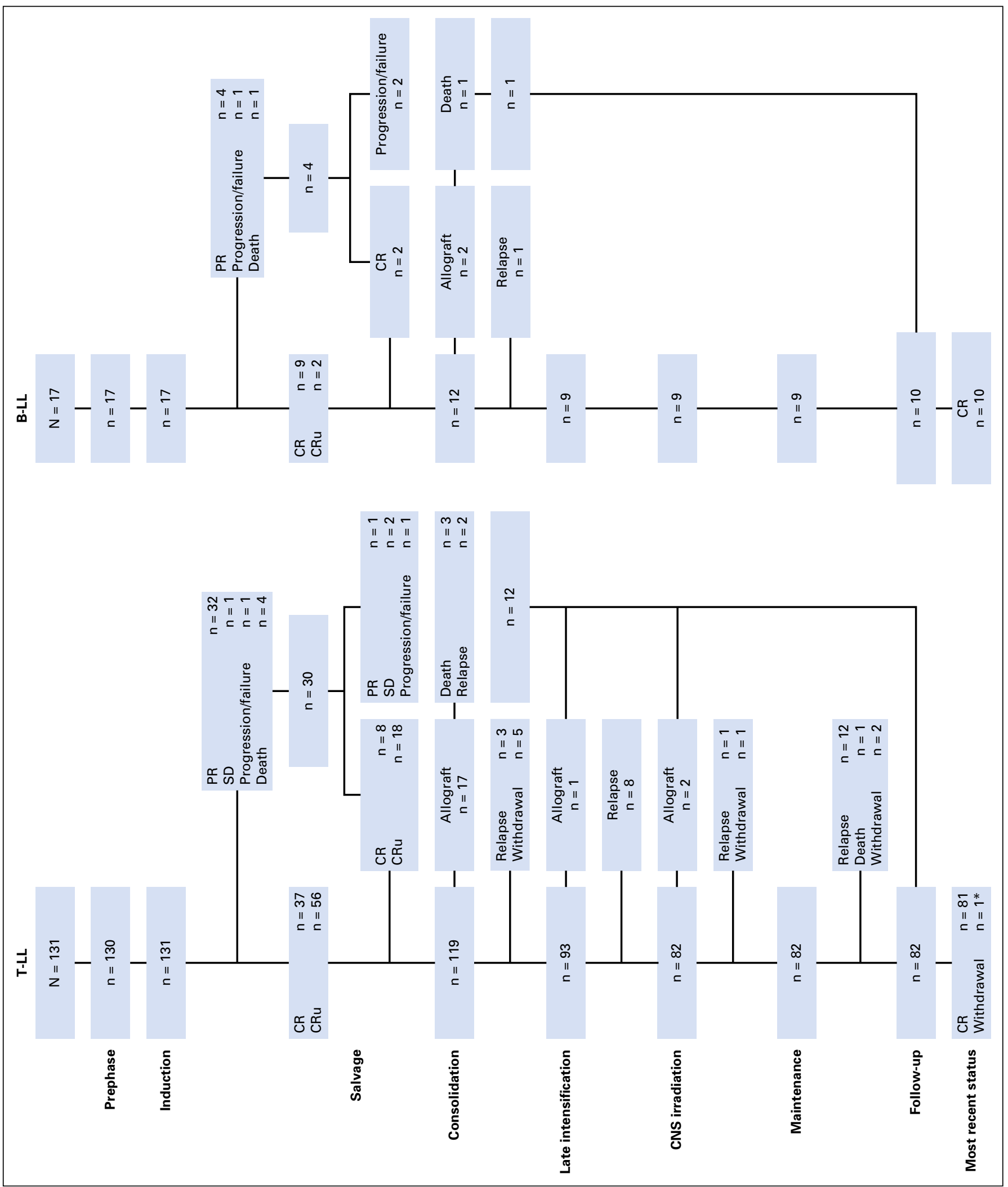

Fig 1. Flow of patients and treatment response. Treatment response was assessed using Cheson criteria. ${ }^{15} \mathrm{~B}-\mathrm{LL}$, B-lineage lymphoblastic lymphoma; $\mathrm{CR}$, complete

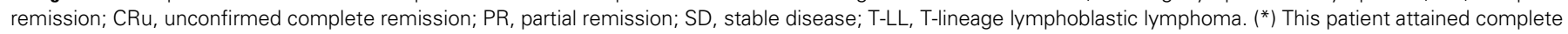
remission after another lymphoma. 


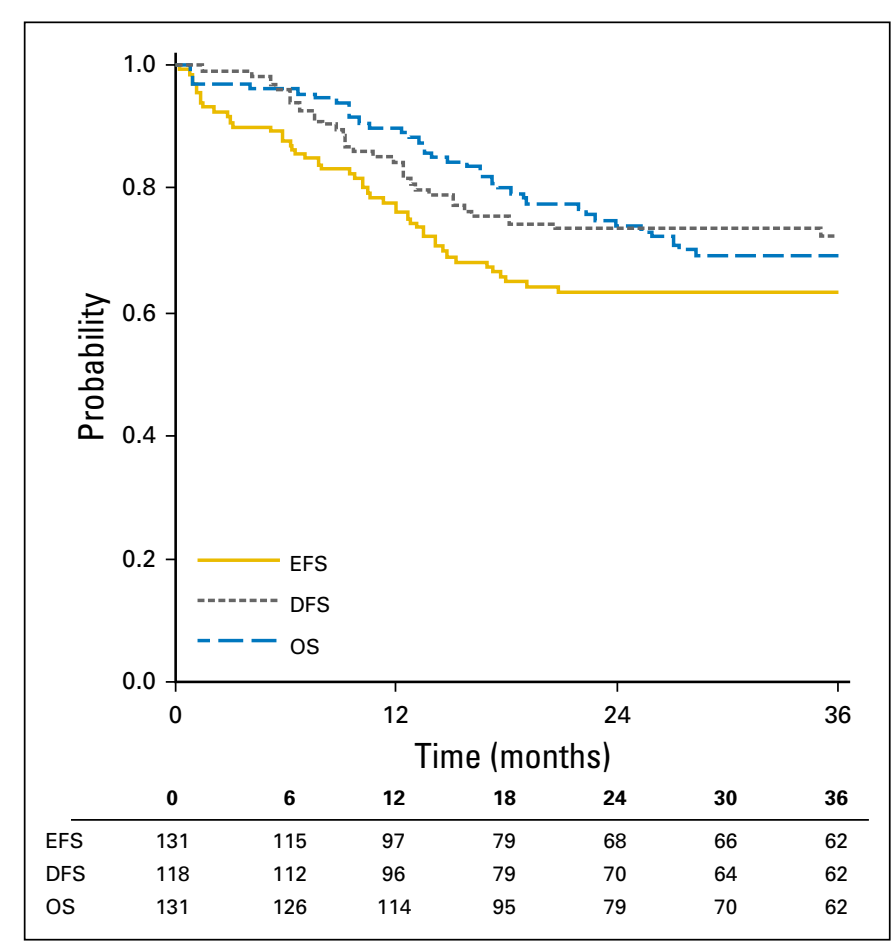

Fig 2. Event-free survival (EFS), disease-free survival (DFS), and overall survival (OS) patient data

TCR gene rearrangement. The absence of TCR $\gamma$ gene rearrangement has been reported to predict a poor prognosis in pediatric T-ALL ${ }^{16}$ and T-LL. ${ }^{12}$ After exclusion of cases with thymoma, following a review of histologic data, six of 54 patients were TCR $\gamma$-negative and 10 of 53 were TCR $\beta$-negative. However, neither subgroup had inferior EFS, DFS, or OS (Data Supplement). 18-deoxyglucose PET scan. 18-deoxyglucose PET scans were available at the end of induction for 68 patients with T-LL and eight patients with B-LL. PET scans were positive for 23 patients with T-LL (33.8\%) and three patients with B-LL (37.5\%). Use of PET scan at the end of induction did not influence the ability to predict EFS, DFS, OS, or mediastinal relapse in patients with T-LL (Table 3), although PET findings at the end of induction correlated with status determined by CT scan (Data Supplement).

HSCT. Of 25 patients with T-LL who were eligible for HSCT (ie, high-risk patients), 17 were transplanted and eight were not. HRs for EFS, DFS, and OS were not significantly different in patients receiving allogeneic HSCT compared with patients not receiving it (Table 3 ).

Other factors. Multivariate analysis showed that LDH level (normal or elevated) was an independent prognostic indicator for EFS (HR, 2.8 [95\% CI, 1.3 to 5.9]; $P=.010$ ) and OS (HR, 3.4 [95\% CI, 1.3 to 8.7]; $P=.012$ ) (Data Supplement). In addition, ECOG-PS score $(\geq 3 v \leq 2)$ was an independent prognostic factor for DFS (HR, 0.1 [95\% CI, 0.0 to 0.7 ]) and OS (HR, 0.1 [95\% CI, 0.0 to 0.6$]$ ), although only two of the 118 patients included in the analysis had an elevated ECOG-PS score $(\geq 3)$. Interestingly, the need for a salvage course to reach CR or CRu was not associated with shorter DFS in patients with CR or CRu.

\section{DISCUSSION}

This study confirms that a pediatric-like ALL therapy improves outcome in adults with LL. The study also supports an independent prognostic value of the four-gene oncogenetic classifier status at diagnosis in patients with T-LL.

With 148 patients enrolled over 8 years, this phase II study is one of the largest conducted to date in adults with LL. Treatment in this study was based on the GRAALL protocol for ALL, ${ }^{7}$ although it

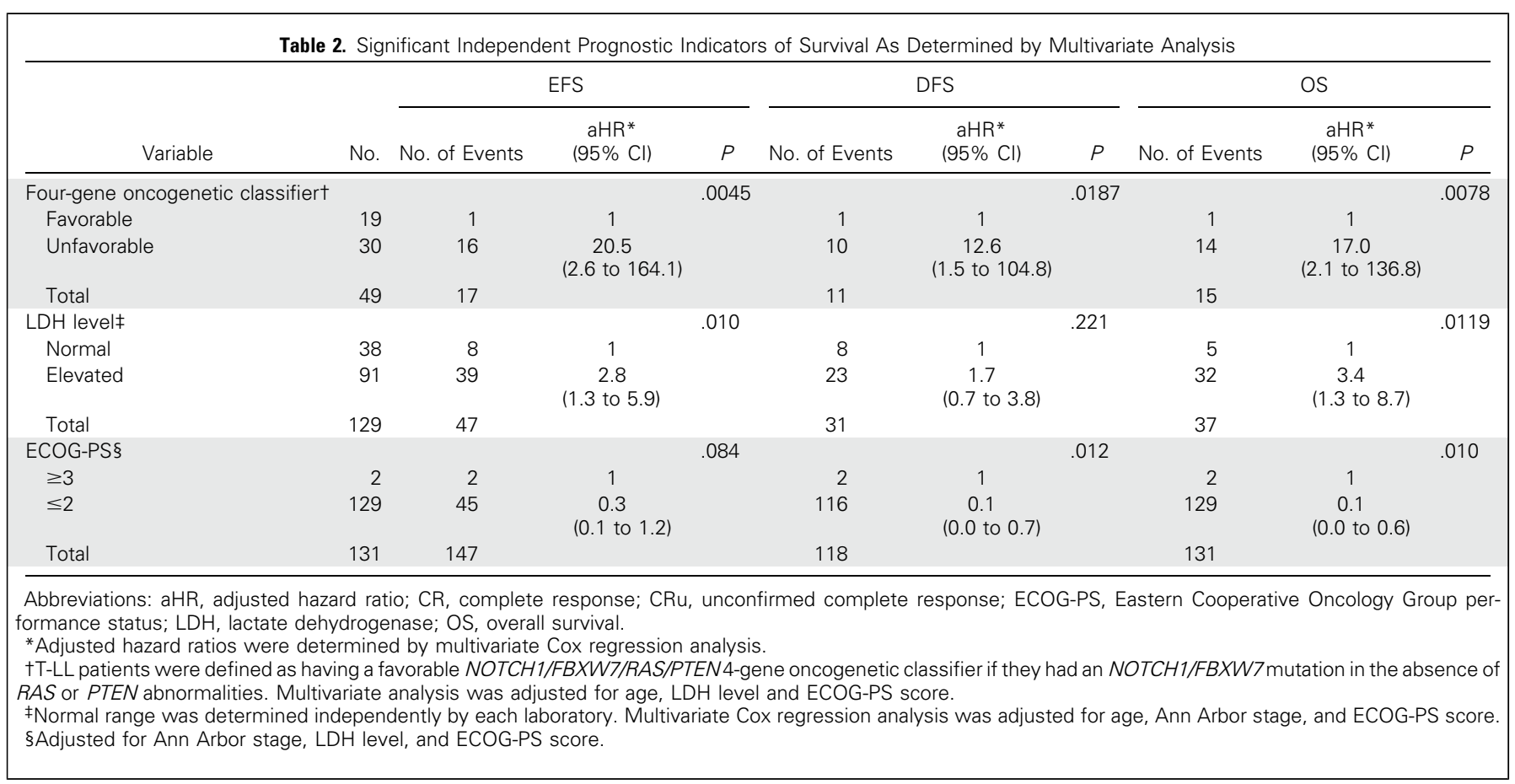


Table 3. Univariate Analysis of Survival According to PET Scan Findings at the End of Induction and According to the Use of HSCT in Patients With T-LL

\begin{tabular}{|c|c|c|c|c|}
\hline Stratification Criterion & No. & Events Before 3 Years & Value $(95 \% \mathrm{Cl})$ & $P$ \\
\hline PET scan* & & & & .1532 \\
\hline \multicolumn{5}{|l|}{ EFS } \\
\hline Total & 68 & 21 & & \\
\hline Positive & 23 & 9 & $\begin{array}{c}59.7 \% \\
\text { (36.7 to } 76.7 \text { ) }\end{array}$ & \\
\hline DFS & & & & 9236 \\
\hline Positive & 19 & 4 & $\begin{array}{c}72.5 \% \\
\text { (39.9 to } 89.4)\end{array}$ & \\
\hline OS & & & & .7845 \\
\hline Total & 68 & 15 & & \\
\hline Negative & 45 & 11 & $\begin{array}{c}73.4 \% \\
\text { (56.9 to } 84.4)\end{array}$ & \\
\hline Negative & 10 & 4 & $\begin{array}{c}50.0 \% \\
\text { (13.7 to } 78.5)\end{array}$ & \\
\hline Positive & 4 & 3 & $\begin{array}{c}25.0 \% \\
(0.9 \text { to } 66.5)\end{array}$ & \\
\hline \multicolumn{5}{|l|}{ HSCT† } \\
\hline \multicolumn{5}{|l|}{ EFS } \\
\hline Total & 25 & 7 & & \\
\hline HSCT & 17 & 4 & $\mathrm{HR}, 1$ & .5061 \\
\hline No HSCT & 8 & 3 & $H R, 0.602$ (0.135 to 2.690$)$ & \\
\hline \multicolumn{5}{|l|}{ DFS } \\
\hline Total & 25 & 8 & & \\
\hline HSCT & 17 & 5 & $\mathrm{HR}, 1$ & .7303 \\
\hline No HSCT & 8 & 3 & $\mathrm{HR}, 0.776$ (0.184 to 3.278$)$ & \\
\hline \multicolumn{5}{|c|}{ 每 } \\
\hline
\end{tabular}

Abbreviations: DFS, disease-free survival; EFS, event-free survival; HR, hazard ratio; HSCT, hematopoietic stem-cell transplantation; OS, overall survival; PET, positron emission tomography; T-LL, T-type lymphoblastic leukemia.

* Survival rates were estimated by Kaplan-Meier analysis and $P$ values were determined by log-rank test.

thazard ratios and $P$ values were determined by a Cox model using time-dependent explanatory variables.

was reinforced by inclusion of a hyperC sequence during induction. The protocol did not include mediastinal irradiation because Hoelzer ${ }^{17}$ et al showed that $50 \%$ of patients with T-LL that received it had mediastinal relapse and because it was not considered a required, validated option.

The general outcome was good: $\mathrm{CR}$ or $\mathrm{CRu}$ was attained in $90.8 \%$ of patients with T-LL and $76.5 \%$ of those with B-LL. Only one-quarter of the patients relapsed or progressed (23\% with B-LL, $26 \%$ with T-LL) after a median follow-up of 3 years. In patients with T-LL, at 3 years, EFS was estimated at $63 \%$, DFS at $72 \%$, and OS at $69 \%$. This compares with other studies using ALL-like intensive chemotherapy regimens in similar patients, which have reported CR rates of $91 \%$ to $93 \%$ and 5 -year DFS of $62 \%$ to $77 \% .^{17-19}$

To date, consistent prognostic factors have not been reported for adults with LL. ${ }^{4}$ The serum LDH level is reported to be a predictor of response to chemotherapy in childhood ALL. ${ }^{20}$ This has also been observed in some adult LL studies ${ }^{21-23}$ but not in others. ${ }^{19,24}$ In the current study, LDH level was an independent prognostic indicator for EFS and OS. Other factors reported to be of prognostic value in adult LL include ECOG-PS, ${ }^{25}$ Ann Arbor stage, ${ }^{23,26}$ bone marrow involvement, ${ }^{27}$ and CNS involvement at presentation. ${ }^{19}$ We did not find Ann Arbor stage, bone marrow involvement, or CNS involvement to be predictive of outcome. ECOG-PS was a significant predictor of outcome, although only two of 118 patients included in the analysis had an elevated score $(\geq 3)$. These results suggest that intensive pediatric-like ALL-like therapy may reduce the prognostic impact of features associated with systemic diffusion of LL.

Analysis of 141 adult diagnostic T-ALL samples collected from patients in the LALA-94 trial and the GRAALL-2003 trial revealed that the presence of $N / F$ mutations was an independent predictor of a better prognosis. ${ }^{10}$ Further analysis of 212 GRAALL samples showed that N/F mutation was an independent predictor of better outcome only in the absence of RAS or PTEN abnormalities (favorable four-gene oncogenetic classifier), whereas all other profiles (unfavorable four-gene classifier) were predictive of a worse outcome (Fig 3). ${ }^{11}$ This four-gene oncogenetic classifier and, to a lesser extent, bone marrow minimal residual disease remained the only two factors associated with relapse incidence in patients with T-ALL in the GRAALL trial. ${ }^{28}$ The fact that the same four-gene 


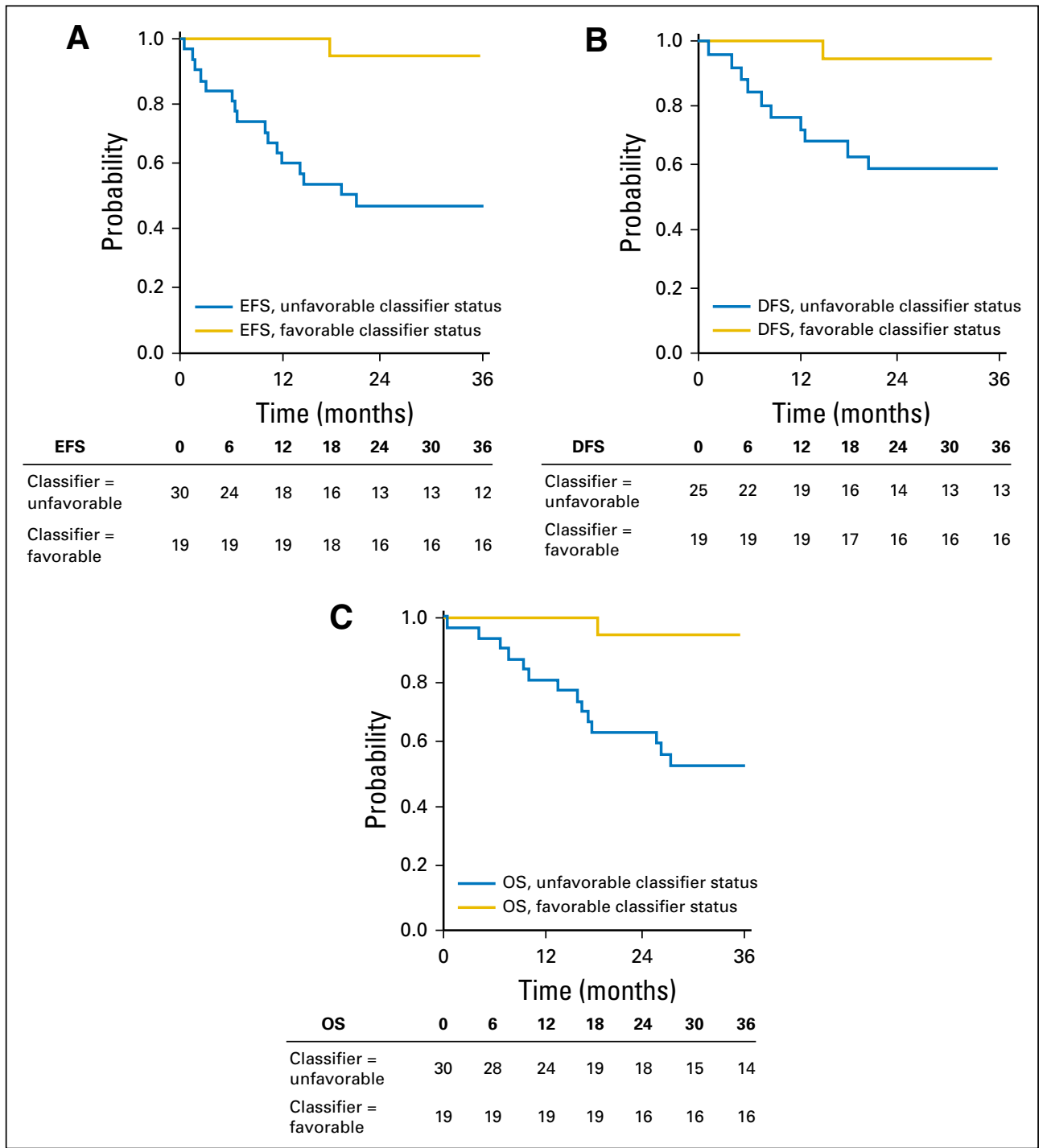

Fig 3. (A) Event-free survival (EFS), (B) disease-free survival (DFS), and (C) overall survival (OS) according to the four-gene oncogenetic classifier. Patients with T-lineage lymphoblastic lymphoma were defined as having a favorable NOTCH1/FBXW7/RAS/ PTEN four-gene oncogenetics if they had an $N / F$ mutation in the absence of $R A S$ or PTEN abnormalities. classifier has strong prognostic value in adult T-LL underlines the similarities between T-ALL and T-LL.

The absence of biallelic TCR $\gamma$ deletion or rearrangement has been shown to predict early treatment failure in pediatric T-ALL. ${ }^{16,29}$ We have also shown that this applies to pediatric patients with T-LL who have mutant $N / F^{12}$ Although we did not confirm this in the current study, a review of histologic data identified three cases of thymoma with an absence of biallelic TCR $\gamma$ rearrangement or deletion, suggesting that TCR rearrangements can be a useful adjunct to histologic review, particularly when DNA diagnostics are already being performed for the four-gene oncogenetic classifier.

In the current study, allogeneic HSCT was offered to patients in $\mathrm{CR}$ or $\mathrm{CRu}$ who needed a second induction salvage course or who had CNS disease. A retrospective multicenter study of 128 patients with LL treated with autologous or allogeneic stem cell transplant found significantly fewer relapses in patients receiving allogeneic HSCT from an HLA-identical sibling. ${ }^{30}$ Also, a small randomized trial of the European Group for Blood and Marrow Transplantation and the United Kingdom Lymphoma Group found a trend for longer DFS but no OS improvement in adult patients with LL receiving allogeneic stem cell transplant compared with those receiving conventional chemotherapy. ${ }^{31}$ In the current study, allogeneic HSCT did not appear to influence outcome, although it was performed in too few patients $(n=20)$ to make definitive conclusions.

We also examined the role of $\left[{ }^{18} \mathrm{~F}\right]$ fluorodeoxyglucose PET in patients with LL. PET is a powerful tool for evaluating responses in lymphomas and other malignancies, and the results correlate with outcome in aggressive NHL and Hodgkin lymphoma. ${ }^{32}$ In this study, PET was not recommended and was only performed in cases of residual masses. We found that having a PET scan did not improve the ability to predict treatment outcome. Similarly, a recent retrospective analysis of data from the Swedish Lymphoma Registry found that having a $\left[{ }^{18} \mathrm{~F}\right]$ fluorodeoxyglucose PET scan does not predict the risk for relapse in patients with T-LL treated with intensive therapy used for patients with ALL. ${ }^{24}$ In contrast, in a recent prospective study of 149 patients with T-LL treated according to the German Multicenter Study Group protocol, PET evaluation yielded positive results in 10 of 22 (45\%) partial 
responders, suggesting that PET can be helpful in making decisions about salvage therapies. ${ }^{33}$ Thus, further study is needed to clarify the utility of PET in the treatment of LL.

This study marks a step forward because it provides information on the biology and treatment of adult LL as a distinct entity. We showed that a pediatric ALL-like treatment provides good results in adult patients with LL patients. We also showed that the four-gene oncogenetic classifier is a useful tool for predicting outcome of the treatment in T-LL.

\section{AUTHORS' DISCLOSURES OF POTENTIAL CONFLICTS} OF INTEREST

Disclosures provided by the authors are available with this article at www.jco.org

\section{AUTHOR CONTRIBUTIONS}

Conception and design: Stéphane Lepretre, Aline Tanguy-Schmidt, Gilles Salles, Thierry Lamy, Marie-Christine Béné, Emmanuel Raffoux, Françoise Huguet, Patrice Chevallier, Serge Bologna, Réda Bouabdallah, Jacques Benichou, Valèrie Tallon-Simon, Carlos Graux, Norbert Ifrah, Elizabeth Macintyre, Hervè Dombret

Provision of study materials or patients: Gilles Salles

Collection and assembly of data: Stéphane Lepretre, Aurore Touzart, JeanMichel Picquenot, Marie-Christine Béné, Josette Brière, Anne Moreau, Valèrie Tallon-Simon, Stéphanie Seris, Elizabeth Macintyre, Hervè Dombret Data analysis and interpretation: Stéphane Lepretre, Aurore Touzart, Thomas Vermeulin, Marie-Christine Béné, Jacques Benichou, Valèrie Tallon-Simon, Stéphanie Seris, Vahid Asnafi, Elizabeth Macintyre, Hervè Dombret

Manuscript writing: All authors

Final approval of manuscript: All authors

\section{REFERENCES}

1. Portell CA, Sweetenham JW: Adult lymphoblastic lymphoma. Cancer J 18:432-438, 2012

2. Hoelzer D, Gökbuget N: Treatment of lymphoblastic lymphoma in adults. Best Pract Res Clin Haematol 15:713-728, 2002

3. Sweetenham JW: Treatment of lymphoblastic lymphoma in adults. Oncology (Williston Park) 23: 1015-1020, 2009

4. Cortelazzo S, Ponzoni M, Ferreri AJ, et al: Lymphoblastic lymphoma. Crit Rev Oncol Hematol 79:330-343, 2011

5. Le Gouill S, Lepretre S, Brière J, et al: Adult lymphoblastic lymphoma: A retrospective analysis of 92 patients under 61 years included in the LNH87/93 trials. Leukemia 17:2220-2224, 2003

6. Dombret $H$, Cluzeau $T$, Huguet $F$, et al: Pediatric-like therapy for adults with ALL. Curr Hematol Malig Rep 9:158-164, 2014

7. Huguet F, Leguay T, Raffoux E, et al: Pediatricinspired therapy in adults with Philadelphia chromosomenegative acute lymphoblastic leukemia: The GRAALL-2003 study. J Clin Oncol 27:911-918, 2009

8. Vardiman JW, Thiele J, Arber DA, et al: The 2008 revision of the World Health Organization (WHO) classification of myeloid neoplasms and acute leukemia: Rationale and important changes. Blood 114:937-951, 2009

9. Carbone PP, Kaplan HS, Musshoff $K$, et al: Report of the Committee on Hodgkin's Disease Staging Classification. Cancer Res 31:1860-1861, 1971

10. Asnafi V, Buzyn A, Le Noir S, et al: NOTCH1/ FBXW7 mutation identifies a large subgroup with favorable outcome in adult T-cell acute lymphoblastic leukemia (T-ALL): A Group for Research on Adult Acute Lymphoblastic Leukemia (GRAALL) study. Blood 113:3918-3924, 2009

11. Trinquand A, Tanguy-Schmidt A, Ben Abdelali $\mathrm{R}$, et al: Toward a NOTCH1/FBXW7/RAS/PTENbased oncogenetic risk classification of adult T-cell acute lymphoblastic leukemia: A Group for Research in Adult Acute Lymphoblastic Leukemia study. J Clin Oncol 31:4333-4342, 2013

12. Callens $C$, Baleydier $F$, Lengline $E$, et al: Clinical impact of NOTCH1 and/or FBXW7 mutations, FLASH deletion, and TCR status in pediatric T-cell lymphoblastic lymphoma. J Clin Oncol 30:1966-1973, 2012

13. Bene MC, Castoldi G, Knapp W, et al: European Group for the Immunological Characterization of
Leukemias (EGIL): Proposals for the immunological classification of acute leukemias. Leukemia 9: 1783-1786, 1995

14. Oken MM, Creech RH, Tormey DC, et al: Toxicity and response criteria of the Eastern Cooperative Oncology Group. Am J Clin Oncol 5:649-655, 1982

15. Cheson BD, Horning SJ, Coiffier B, et al: $\mathrm{NCl}$ Sponsored International Working Group: Report of an international workshop to standardize response criteria for non-Hodgkin's lymphomas. J Clin Oncol 17: 1244, 1999

16. Gutierrez A, Dahlberg SE, Neuberg DS, et al: Absence of biallelic TCR $\gamma$ deletion predicts early treatment failure in pediatric T-cell acute lymphoblastic leukemia. J Clin Oncol 28:3816-3823, 2010

17. Hoelzer D, Gökbuget N, Digel W, et al: Outcome of adult patients with T-lymphoblastic lymphoma treated according to protocols for acute lymphoblastic leukemia. Blood 99:4379-4385, 2002

18. Cortelazzo S, Intermesoli T, Oldani $E$, et al: Results of a lymphoblastic leukemia-like chemotherapy program with risk-adapted mediastinal irradiation and stem cell transplantation for adult patients with lymphoblastic lymphoma. Ann Hematol 91: 73-82, 2012

19. Thomas DA, O'Brien S, Cortes J, et al: Outcome with the hyper-CVAD regimens in lymphoblastic lymphoma. Blood 104:1624-1630, 2004

20. Pui CH, Dodge RK, Dahl GV, et al: Serum lactic dehydrogenase level has prognostic value in childhood acute lymphoblastic leukemia. Blood 66: 778-782, 1985

21. Morel $P$, Lepage E, Brice $P$, et al: Prognosis and treatment of lymphoblastic lymphoma in adults: A report on 80 patients. J Clin Oncol 10:1078-1085, 1992

22. Hu Y, Zhao $X, W u L L$, et al: Comparison of HyperCVAD regimen and CHOP regimen in treating patients with lymphoblastic lymphoma [in Chinese]. Sichuan Da Xue Xue Bao Yi Xue Ban 45:680-684, 2014

23. Gu Y, Pan Y, Meng B, et al: High levels of bcl-2 protein expression do not correlate with genetic abnormalities but predict worse prognosis in patients with lymphoblastic lymphoma. Tumour Biol 34: 1441-1450, 2013

24. Ellin $F$, Jerkeman $M$, Hagberg $H$, et al: Treatment outcome in T-cell lymphoblastic lymphoma in adults: A population-based study from the Swedish Lymphoma Registry. Acta Oncol 53:927-934, 2014
25. Tilak TV, Raina V, Kumar L, et al: Superior vena cava syndrome and poor performance status at presentation affect survival in mediastinal Tlymphoblastic lymphoma-a single institute experience from India. Ann Hematol 92:917-923, 2013

26. Pan Y, Liu WP, Li JF, et al: A clinicopathological study of 96 cases of lymphoblastic lymphoma [in Chinese]. Zhonghua Xue Ye Xue Za Zhi 26:218-222, 2005

27. Song KW, Barnett MJ, Gascoyne RD, et al: Primary therapy for adults with T-cell lymphoblastic lymphoma with hematopoietic stem-cell transplantation results in favorable outcomes. Ann Oncol 18:535-540, 2007

28. Beldjord K, Chevret S, Asnafi V, et al: Group for Research on Adult Acute Lymphoblastic Leukemia (GRAALL): Oncogenetics and minimal residual disease are independent outcome predictors in adult patients with acute lymphoblastic leukemia. Blood 123:3739-3749, 2014

29. Yang YL, Hsiao CC, Chen HY, et al: Absence of biallelic TCR $\gamma$ deletion predicts induction failure and poorer outcomes in childhood T-cell acute lymphoblastic leukemia. Pediatr Blood Cancer 58:846-851, 2012

30. Levine JE, Harris RE, Loberiza FR Jr, et al: Lymphoma Study Writing Committee, International Bone Marrow Transplant Registry and Autologous Blood and Marrow Transplant Registry: A comparison of allogeneic and autologous bone marrow transplantation for lymphoblastic lymphoma. Blood 101:2476-2482, 2003

31. Sweetenham JW, Santini G, Qian W, et al: High-dose therapy and autologous stem-cell transplantation versus conventional-dose consolidation/ maintenance therapy as postremission therapy for adult patients with lymphoblastic lymphoma: Results of a randomized trial of the European Group for Blood and Marrow Transplantation and the United Kingdom Lymphoma Group. J Clin Oncol 19: 2927-2936, 2001

32. Seam $P$, Juweid ME, Cheson BD: The role of FDG-PET scans in patients with lymphoma. Blood 110:3507-3516, 2007

33. Gökbuget $N$, Wolf $A$, Stelljes $M$, et al: Favorable outcome in a large cohort of prospectively treated adult patients with T-lymphoblastic lymphoma (T-LBL) despite slowly evolving complete remission assessed by conventional radiography. Presented at the 56th Annual ASH Annual Meeting and Exposition, San Francisco, CA, December 6-9, 2014 


\section{Affiliations}

Stéphane Lepretre, Valérie Tallon-Simon, and Stéphanie Seris, Institut National de la Santé et de la Recherche Médicale (INSERM) U918, University of Rouen, Centre de Lutte contre le Cancer de Haute-Normandie (CLCC) H. Becquerel; Thomas Vermeulin and Jacques Benichou, Centre Hospitalier Universitaire (CHU) Charles Nicolle and INSERM U657, University of Rouen; Jean-Michel Picquenot, CLCC H. Becquerel, Rouen; Aurore Touzart, Vahid Asnafi, and Elizabeth Macintyre, University Paris Descartes Sorbonne Cité, Institut Necker-Enfants Malades, INSERM U1151, and Assistance Publique-Hôpitaux de Paris, Hôpital Necker Enfants-Malades; Emmanuel Raffoux and Hervé Dombret, Hôpital Saint-Louis, Assistance Publique-Hôpitaux de Paris, Université Paris Diderot; Josette Brière, Hôpital Saint-Louis, Assistance Publique-Hôpitaux de Paris, Paris; Aline Tanguy-Schmidt and Norbert Ifrah, Maladies du sang CHU Angers, INSERM U892, and University of Angers, Angers; Gilles Salles, CHU Centre Hospitalier Lyon-Sud, Pierre Bénite; Thierry Lamy, CHU Ponchaillou, Rennes; Anne Moreau, Marie-Christine Béné, and Patrice Chevallier, CHU Hôtel-Dieu, Nantes; Françoise Huguet, CHU Purpan, Toulouse; Serge Bologna, CHU Vandoeuvre-les-Nancy, Vandoeuvre-les-Nancy; Réda Bouabdallah, CLCC P. Calmette, Marseille, France; and Carlos Graux, Godinne University Hospital, Yvoir, Belgium.

\section{Order ASCO Answers Fact Sheets for Your Office or Waiting Room}

ASCO Answers fact sheets provide an introduction to more than 50 types of cancer and cancer topics, including treatments and side effects. Download fact sheets at cancer.net/ascoanswers or order them for your practice through the ASCO University Bookstore at www.cancer.net/estore. All fact sheets ship for free and ASCO members receive a $20 \%$ discount. 


\section{AUTHORS' DISCLOSURES OF POTENTIAL CONFLICTS OF INTEREST}

Pediatric-Like Acute Lymphoblastic Leukemia Therapy in Adults With Lymphoblastic Lymphoma: The GRAALL-LYSA LL03 Study

The following represents disclosure information provided by authors of this manuscript. All relationships are considered compensated. Relationships are self-held unless noted. I = Immediate Family Member, Inst = My Institution. Relationships may not relate to the subject matter of this manuscript. For more information about ASCO's conflict of interest policy, please refer to www.asco.org/rwc or jco.ascopubs.org/site/ifc.

\section{Stéphane Lepretre}

No relationship to disclose

\section{Aurore Touzart}

No relationship to disclose

Thomas Vermeulin

No relationship to disclose

\section{Jean-Michel Picquenot}

No relationship to disclose

\section{Aline Tanguy-Schmidt}

No relationship to disclose

\section{Gilles Salles}

Honoraria: Genentech, Amgen, Mundipharma, Sanofi

Consulting or Advisory Role: Genentech, Gilead Sciences, Janssen

Pharmaceuticals, Mundipharma, Celgene

Research Funding: Genentech,

Travel, Accommodations, Expenses: Genentech

Thierry Lamy

No relationship to disclose

Marie-Christine Béné

Research Funding: Beckman Coulter

\section{Emmanuel Raffoux}

No relationship to disclose

Françoise Huguet

No relationship to disclose

Patrice Chevallier

No relationship to disclose

\section{Serge Bologna}

No relationship to disclose

Réda Bouabdallah

No relationship to disclose

Jacques Benichou

No relationship to disclose

Josette Brière

No relationship to disclose

Anne Moreau

No relationship to disclose

Valérie Tallon-Simon

No relationship to disclose

Stephanie Seris

No relationship to disclose

Carlos Graux

No relationship to disclose

Vahid Asnafi

No relationship to disclose

Norbert Ifrah

No relationship to disclose

Elizabeth Macintyre

Patents, Royalties, Other Intellectual Property: Participate in royalty sharing agreement

Hervé Dombret

Research Funding: Roche 


\section{Acknowledgment}

We thank the anatomic pathologists of the LYSA for data review and the clinical research associates and GRAALL and LYSA investigators. Medical writing was provided by Phillip Leventhal, $\mathrm{PhD}$ (4Clinics, Paris, France). 